\title{
APLIKASI SISTEM INFORMASI UNTUK ONLINE REKRUTMEN PADA PT. YUASA BATTERY INDONESIA KEBON NANAS TANGERANG
}

\author{
Sugeng Santoso ${ }^{1}$ \\ Azizah Handayani Putri ${ }^{2}$ \\ Ifoh Basaria ${ }^{3}$ \\ E-mail:sugeng.santoso@raharja.info,azizah@raharja.info,ifoh@raharja.info
}

\begin{abstract}
ABSTRAK
Perkembangan teknologi pada saat ini sudah berkembang begitu pesatnya, media internet pun sudah banyak digunakan untuk mendapatkan informasi, khususnya dalam hal lowongan pekerjaan. Namun pengolahan data perekrutan karyawan pada PT. Yuasa Battery Indonesia masih menggunakan sistem yang manual. Sehingga pada proses perekrutan karyawan pun masih kurang efisien.Pada permasalahan ini, penulis mengambil kesimpulan dan jalan keluar, dengan melakukan analisa sistem yg berjalan dengan menggunakan beberapa metode antara lain, metode pengumpulan data yaitu observasi dan studi pustaka, metode analisa dan perancangan.Selanjutnya penulis melakukan usulan perancangan sistem yg akan di implementasikan dari hasil analisa yang telah dilakukan. Dari hasil di atas, maka penulis melakukan penelitian dan mengusulkan perancangan sistem perekrutan karyawan pada perusahaan PT. Yuasa Battery Indonesia agar dapat memberikan pelayanan informasi yang bermutu dan uptodate bagi para calon pelamar. Hasil dari penelitian ini dapat mempermudah para calon karyawan dalam mencari informasi mengenai pekerjaan.Selain itu juga mempermudah bagian personalia dalam penginputan data karyawan.
\end{abstract}

Kata Kunci : Sistem, Informasi, Rekrutmen.

\begin{abstract}
The development of technology nowadays has grown so rapidly, the Internet media has been widely used to obtain information, particularly in terms of jobs. However data processing recruitment of employees at PT. Yuasa Battery Indonesia still uses a manual system. So that the recruitment process is still less efficient. In this problem, the authors conclude and the way out, by analyzing the system that runs using several methods, among others, data collection methods, namely observation and literature, methods of analysis and design. Furthermore, the authors do a system design proposal which will be implemented from the analysis that has been done. From the above results, the authors conducted a study and proposed system design recruitment company PT. Yuasa Battery Indonesia in order to provide quality service and up to date information for potential applicants. The results of this study may facilitate the prospective employees in seeking information about the job. It is also easier for the personnel in the input data of employees.
\end{abstract}

Keywords: Systems, Information, Recruitment. 


\section{PENDAHULUAN}

Perkembangan

kebutuhansistem komputerisasi juga sejalan dengan berkembangnya ilmu pengetahuan dan teknologi yang sangat pesat khususnya ilmu komputer.Penggunaan perangkat komputer dapat dilengkapi dengan program aplikasi sehingga dapat memberikan hasil yang berkualitas dan juga menjadi lebih optimal.

Penggunaan

komputer juga mempengaruhi bagaimana sebuah prosedur yang ada dalam sebuah institusi, organisasi maupun perusahaan.Salah satu faktor yang menjadi topik dalam penelitian dan penulisan laporan jurnal ini adalah sistem penerimaan karyawan baru yang dapat ditampilkan secaraonline pada PT. Yuasa Battery Indonesia.Sumber Daya Manusia (SDM) terus dirasakan sebagai salah satu aset yang paling penting dan berharga dalam perusahaan.Karena SDM memainkan peran sebagai pemberi ide, pendorong dan pelaksana ide, juga kegiatan-kegiatan lain dalam perusahaan untuk mencapai tujuan perusahaan.

Dalam menjalankan kegiatan perusahaan, tidak hanya dituntut kemajuan bisnis atau pengguna teknologi yang canggih, tetapi juga perlu diperhatikan dari sumber daya manusianya, yaitu bagaimana sebuah perusahaan dapat memiliki aset berupa sumber daya manusia yang mempunyai kedisiplinan yang tinggi dankinerja yang sesuai dengan kebutuhan perusahaan.

Dari hasil analisa kebutuhan

PT. Yuasa Battery Indonesia masih menggunakan sistem manual dalam perekrutan karyawan.Dimana setiap calon karyawan baru harus datang ke perusahaan membawa lamaran untuk mengikuti tes dan wawancara secara langsung, kemudian harus menunggu hasil tes seleksi yang akan diberitahukan oleh perusahaan tersebut melalui telepon ataupun menggunakan media komunikasi lain. Dari permasalahan yang timbul maka dibuatlah sebuah sistem informasi rekruitmen online untuk memudahkan proses lamaran kerja untuk para calon karyawan baru. System informasi rekruitmen online merupakan upaya yang diusulkannya system ini bertujuan untuk memberikan keefektifan dan efisiensi waktu dan prosesn penerimaan karyawan baru, selain itu untuk menikngkatkan kinerja pegawai sehingga tidak terjadi kesalahan pada saat jam kerja

\section{PERMASALAHAN}

Dalam studi kasus tentang lowongan pekerjaan di PT. Yuasa Battery Indonesia ini, penulis menemukan masalah yang biasa terselesaikan dengan adanya dukungan dari sistem informasi yang baik. Permasalahan yang ada di perusahaan tersebut adalah proses penerimaan karyawan baru masih dilakukan secara manual dalam hal proses pengolahan data perekrutan karyawan baru. Maka dari itu terjadi kecurangan pada proses penerimaan karyawan baru, seperti pengkoreksian test seleksi yang kurang teliti, dan proses pengumuman yang diberikan relatif sangat lama. Proses pengolahan data yang lambat dapat 
mengakibatkan lambatnya penyampaian informasi.Berdasarkan permasalahan diatas, maka diperlukan adanya system informasi perekrutan secara online yang dapat meminimalisirkan permasalahan yang ada, yaitu dengan membangun sistem yang dapat membantu bagian pegawai dalam melakukan proses pengolahan data dan membantu para pegawai dalam melakukan pengkoreksian test seleksi para calon karyawan baru.

\section{PEMBAHASAN}

Pada penelitian ini, penulis membahas tentang perekrutan karyawan baru di PT. Yuasa Battery Indonesia, proses perekrutan yang berjalan saat ini masih dilakukan secara manual dalam hal proses pengolahan data dan penseleksian dalam penerimaan karyawan baru. Karyawan harus datang ke perusahaan menaruh surat lamaran, lalu datang kembali untuk penyeleksian test karyawan, dan menunggu hasil penerimaan test seleksi tersebut. Namun dalam penilaian test tersebut pegawai mengalami kesulitan dalam pengolahan data karyawan baru, sehingga terkadang terjadi kesalahan dalam pengoreksian dan proses pengolahan data yang lambat sehingga mengakibatkan lambatnya penyampaian informasi. Oleh sebab itu, diperlukan system informasi yang dapat memecahkan masalah tersebut yang cepat dan akurat.

Penulis mengusulkan sistem informasi perekrutan karyawan secara online agar dapat membantu pegawai dalam pengolahan data karyawan baru.System yang diusulkan juga dengan menggunakan aplikasi web, yang mana bisa diakses dimanapun dan kapanpun.Sistem yang diusulkan bertujuan untuk menghasilkan informasi yang lebih mudah diakses oleh para calon karyawan baru dan pegawai perusahaan. Dan penilaian test karyawan secara online dapat dilakukan apabila calon karyawan sudah melakukan test di dalam web tersebut.

Pada penulisan jurnal ilmiah ini, pembahasan akan menitikberatkan pada point-point berikut :

1. Prototype perancangan sistem informasi perekrutan karyawan secara online pada PT. Yuasa Battery Indonesia Kebon Nanas, Tangerang

2. Proses alur kegiatan perekrutan karyawan baik dalam proses pendaftaran, proses seleksi dan proses penerimaan.

3. Penilaian hasil test seleksi karyawan baru yang akan dijadikan laporan sebagai bahan pertimbangan untuk pengambilan keputusan kinerja karyawan.

\section{LITERATURE RIVIEW}

Dalam upaya mengembangkan sistem informasi perekrutan karyawan baru ini diperlukan studi pustaka sebagai salah satu penerapan metode penelitian yang akan dilakukan. Adapun Literature Review sebagai landasan dalam mendukung penelitian adalah sebagai berikut:

1. Penelitian yang dilakukan oleh Tri Pujadi (Jurnal CCIT, 2010) dengan judul "Design ComputerBased Application for Recruitment and Selection Employee at PT. 
Indonusa Telemedia”. Pada penelitian sistem ini diciptakan dengan menggunkan VB 6.0, Ms.Acces Database dan aplikasi ini dapat menampilkan laporan baik berbentuk Microsoft Office ataupun microsoft excel. Penulis melakukan penelitian di level berikutnya yaitu membuat $e$ recruitment dengan berbasis web menggunakan PHP, dreamweaver CS3 dan MySQL sebagai databasenya.

2. Penelitian yang dilakukan oleh Sri Yuliasih (2009)Penelitian yang telah dilakukan oleh Sri Yuliasih berjudul "Analisa Sistem Informasi Penerimaan Kepegawaian Pada Pemerintahan Kota Tangerang”. Pada penelitiannya hanya dibatasi pada sistem penerimaan pegawai, mulai dari analisa masukan (input) sampai pada prosedur-prosedur yang berhubungan dengan proses penerimaan kepegawaian. Dengan proses seperti itu akan Program yang digunakan untuk pembuatan sistem yang diusulkan yaitu menggunakan visual basic dengan database-nya yaitu Microsoft Access.

3. Penelitian yang dilakukan oleh Andri Fajar Sektiawan (STMIK Raharja, 2010) dengan judul "Perancangan Sistem Perekrutan 60 Pegawai Berbasis Web Pada PT. Pacific Food Indonesia”. Pada penelitian ini sistem yang sedang berjalan dalam perekrutan karyawan masih menggunakan sistem manual yang dilakukan dengan cara penempelan pamplet atau dengan cara pemberitahuan kepada karyawan lain, untuk itu dibuat website yang diharapkan memberi nilai tambah dalam penyampaian informasi kegiatan perekrutan karyawan, dan dibuat program perekrutan karyawan guna mempermudah pekerjaan bagian terkait. Penulis melakukan penelitian di level berikutnya yaitu membuat e-recruitment dengan basis web yang tidak hanya untuk memudahkan pelamar mendapatkan informasi lowongan pekerjaan tetapi pelamar dapat langsung melamar pekerjaan secara online.

4. Penelitian yang dilakukan oleh Aakash Gopalia (Oxford Brookers University). "Effectiveness of Online Recruitment and Selection Process : A Case of Tesco". Pada penelitian ini sistem ini menggunakan web based software application untuk mengisi lowongan. Dengan menggunakan form online erecruitmrnt untuk merekrut pegawai dinilai efektif dan menghemat waktu bagi para kandidat, selain itu menurunkan biaya perekrutan dan mendapatkan kandidat yang berkualitas dengan proses seleksi yang cepat. Penulis melakukan penelitian di level berikutnya yaitu membuat erecruitment dengan basis web yang tidak hanya untuk memudahkan pelamar mendapatkan informasi lowongan pekerjaan tetapi pelamar dapat langsung melamar pekerjaan secara online. Dan dalam tahapan seleksi 61 tes penulis 
menambahkan tes online yang dilakukan pelamar di perusahaan.

\section{PEMECAHAN MASALAH}

Untuk mengatasi permasalahan seperti yang telah dijelaskan diatas,maka dibutuhkan sistem perekrtuan yang dapat meminimalkan permasalahan yang ada.Sistem informasi perekrutan karyawan baru merupakan salah satu upaya untuk membantu kelancaran instansi sehingga data yang di dapat lebih tepat dan akurat. Sistem ini akan membantu perekrutan karyawan baru di PT. Yuasa Battery Indonesia yang selama ini masih berjalan secara manual. Didalam sebuah sistem informasi perekrutan karyawan baru yang berbasis web,dimana semua data yang ada tersimpan didalam suatu database. Sistem informasi perekrutan karyawan baru di PT. Yuasa Battery Indonesia dibangun menggunakan rancangan sistem dengan menggunakan bahasa pemograman PHP (Hypertext Preprosessor) dan database MySQL.

\section{ANALISA SISTEM PEREKRUTAN KARYAWAN}

Untuk membangun sebuah sistem maka diperlukan rancangan diagram untuk memudahkan dalam melakukan rancangan sistem yang dibuat dapat terstruktur, rancangan sistem dibuat menggunakan UML (Unified Modeling Language).Berikut UML system informasi perekrutan karyawan secara online pada PT. Yuasa Battery Indonesia :

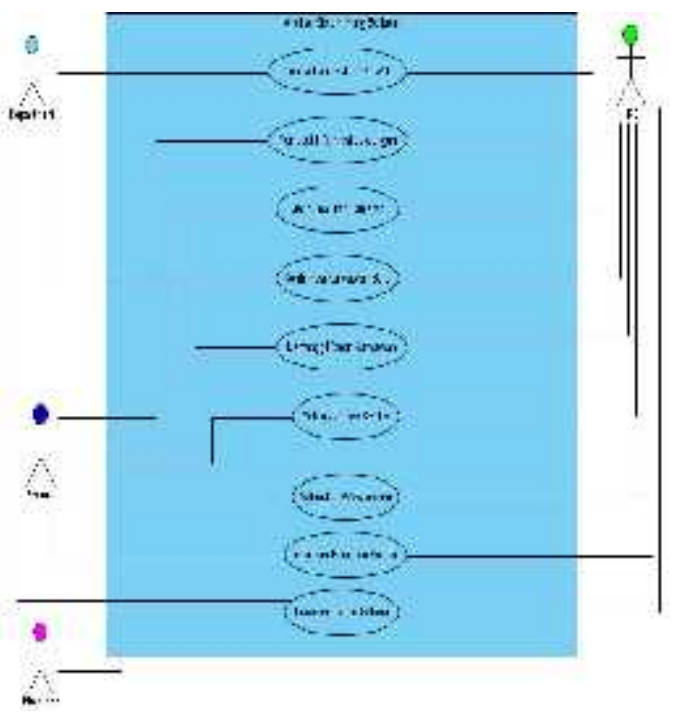

\section{IMPLEMETASI}

Untuk dapat mengakses Sistem Informasi Perekrutan Karyawan Baru cukup mengetik pada windows explorer ruang kosong address dengan mengetik http:/localhost/perekrutan karyawan baru yang kemudian akan muncul tampilan menu login seperti dibawah ini.

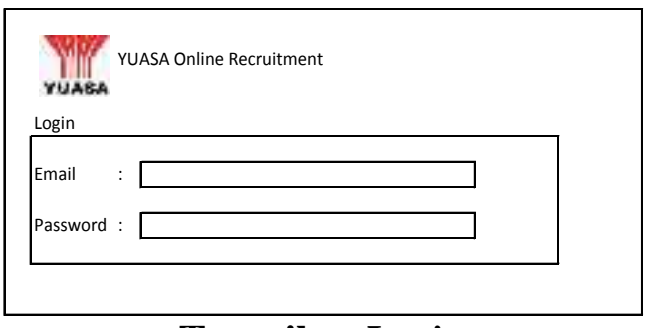

Tampilan Login

Tampilan home digunakan oleh admin dan seluruh pegawai yang ada di PT. Yuasa Battery jika sudah memiliki akun untuk login. Jika pegawai belum memiliki akun maka klik tombol signup untuk melakukan registrasi terlebih dahulu, pada saat mengklik tombol maka akan muncul tampilan home seperti dibawah ini. 


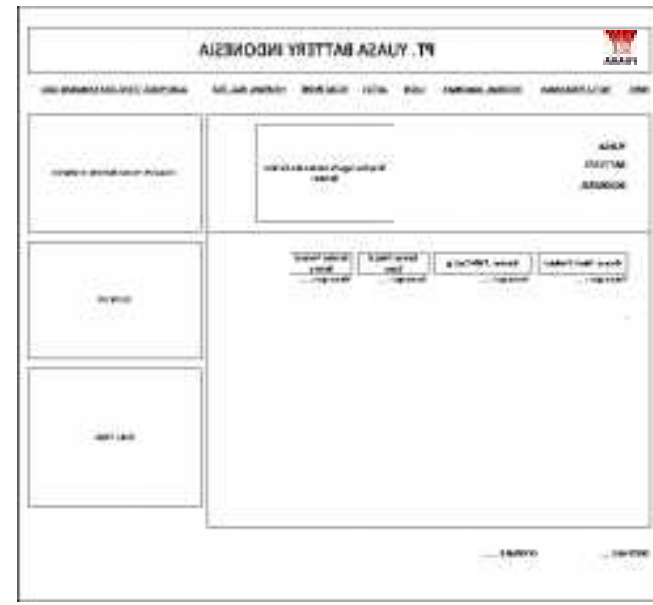

Tampilan Home

Tampilan home merupakan tampilan awal saat masuk kedalam aplikasi perekrutan karyawan. Dibawah ini, tampilan daftar digunakan oleh admin dan seluruh pegawai yang ada di PT. Yuasa Battery Indonesiajika sudah memiliki akun untuk login. Jika pegawai belum memiliki akun maka klik tombol signup untuk melakukan registrasi terlebi dahulu, pada saat mengklik tombol signup maka akan muncul tampilan daftar seperti dibawah ini.

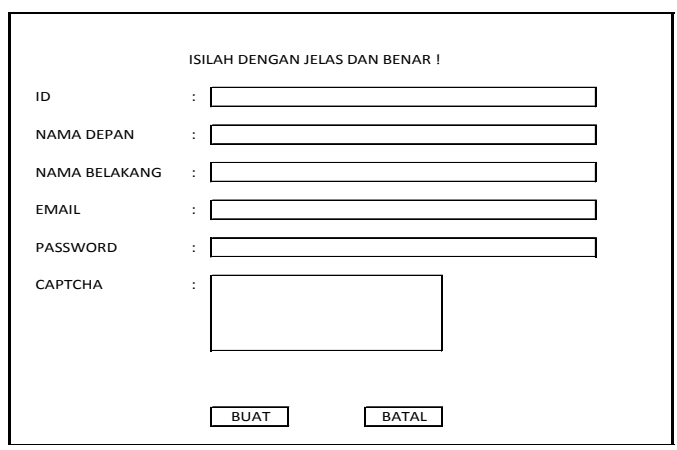

Tampilan Daftar

Setelah selesai mengisi pada tampilan daftar maka pegawai dapat mengakses sistem ini, dibawah ini adalah tampilan data calon karyawan PT. Yuasa Battery seperti tampilan dibawah ini, yang harus dilengkapi sebelum mengikuti tes online. Sebagai kelengkapan dan syarat mengikuti test online.

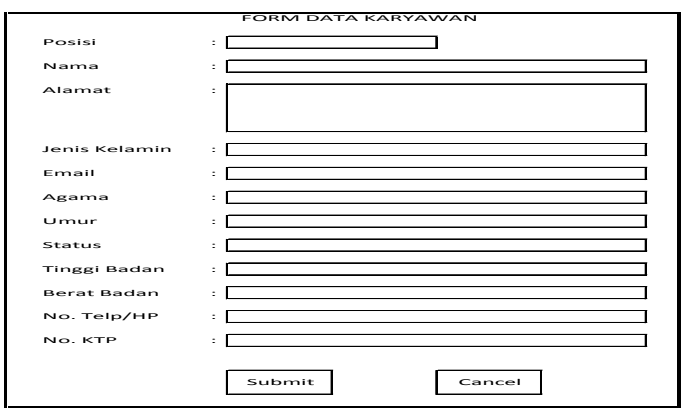

\section{Tampilan Data Calon Karyawan}

Pada saat calon karyawan baru PT. Yuasa Battery Indonesia berhasil melakukan daftar login, kemudian calon karyawan baru mengisi form data calon karyawan.Dan mengisi tes online seperti tampilan dibawah ini.

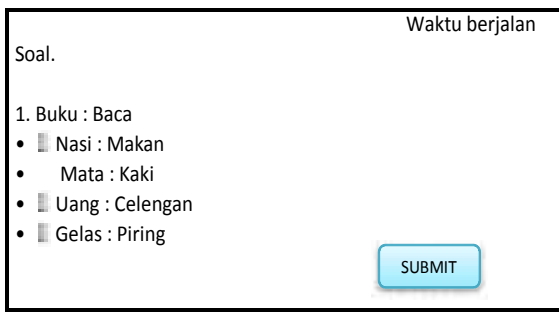

\section{Tampilan Tes Online}

Setelah itu muncul penilaian atau hasil tes seleksi online yang dapat dilihat dua hari setelah melakukan tes online.Seperti tampilan dibawah ini. 


\begin{tabular}{|c|c|c|c|c|c|}
\hline No & ID & Nama & Tgl Input Tes & Hasil Tes & Keterangan \\
\hline 1 & 2 & Ana & 01/06/14 & 50 & Gagal \\
\hline 2 & 3 & Ani & 01/07/14 & 45 & Gagal \\
\hline 3 & 5 & Andi & 01/08/14 & 80 & Lulus \\
\hline 4 & 4 & Budi & $01 / 09 / 14$ & 88 & Lulus \\
\hline 5 & 7 & Siti & 01/10/14 & 90 & Lulus \\
\hline 6 & 8 & Erna & 01/11/14 & 75 & Lulus \\
\hline 7 & 10 & Mutya & $01 / 12 / 14$ & 40 & Gagal \\
\hline 8 & 11 & Juli & 01/13/14 & 85 & Lulus \\
\hline 9 & 12 & Satriyo & $01 / 14 / 14$ & 35 & Gagal \\
\hline 10 & 15 & Ctye & $01 / 15 / 14$ & 100 & Lulus \\
\hline
\end{tabular}

Tampilan Hasil Tes Online

\section{KESIMPULAN}

Setelah menyelesaikan laporan ini penulis dapat menyimpulkan dalam sistem perekrutan karyawan yang baru pada PT. Yuasa Battery Indonesia, dapat dibangun sistem perekrutan karyawan secara online.Sistem perekrutan karyawan yang masih berjalan pada PT. Yuasa Battery Indonesia belum memenuhi standard yang telah ditetapkan, karena masih menggunakan sistem yang manual dalam penginputan data karyawan yaitu dengan cara menggunakan aplikasi Microsoft Excel,kurang efisien dan memakan waktu yang lama. Dan penilaian hasil test calon karyawan secara online, dapat dilakukan dengan cara membuka website rekrutmen online dengan menggunakan username masingmasing. Kemudian hasil tersebut akan tampil setelah dua hari melakukan tes pada page hasil tes seleksi yang telah disediakan.

\section{DAFTAR PUSTAKA}

1. Pujadi, Tri. 2011. "Design Computer-Based Application For Recruitment And Selection Employee At PT. Indonesia Telemedia." Vol.4 No.2-Januari 2011 ISSN: 1978-8282 STMIK Raharja.

2. Gopalia, Aakash (Oxford Brookers University).

Effectiveness of Online Recruitment and Selection Process : Case of Tesco

3. Sektiawan, Fajar Andri (2010) "Perancangan Sistem Perekrutan 60 Pegawai Berbasis Web Pada PT. Pacific Food Indonesia" STMIK Raharja.

4. Yuliasih, Sri (2009) "Analisa Sistem Informasi Penerimaan Kepegawaian Pada Pemerintahan Kota Tangerang".

5. Herlawati, Prabowo Pudjo Widodo. 2011. "Menggunakan UML Unified Modeling Language". Bandung : Informatika.

6. Meiastoko, dody. 2013. "Implementasi Sistem Informasi Sumber Daya Manusia Dalam, Kegiatan Rekruitmen Karyawan". Jurnal Administrasi Bisnis (JAB) Vol.6 No.2-September 2013 